\title{
ATTITUDE AS A DETERMINANT IN SPELLING EFFICIENCY IN IMMEDIATE AND DELAYED RECALL
}

\author{
G. F. ARPS \\ Ohio Stale University
}

\section{INTRODUCTION}

Random information in and out of school points to increased orthographic viciousness. No inconsiderable percentage of university students, with duly attested credentials from accredited secondary schools, present in their written reviews and examinations, models of inaccurate spelling. Various reasons are assigned for this increased deficiency, chief among them being the enrichment of the elementary and secondary programs and the consequent shortening of the time devoted to spelling. Elimination of new subjects, introduced through social necessity, in the interest of spelling is impossible because such subjects represent this generation's advances and needs. If educational procedure is to avoid over-taxation of children and at the same time insure the learning of an increased bulk of information, it appears imperative that educational practice should improve the teaching technique on the one hand and devise more economic methods of learning on the other. The child of the present must learn more economically.

General denunciation, now prevalent, of the inconsistent and irrational forms of the English language by no means meets the difficulty, but may, by the overzealous "confound confusion." It would seem that improvement in the technique of spelling resulting in greater efficiency and economy in learning offers a desirable auxiliary to conservative orthographic reform.

'The Unpopular Review: "Az tu the long sowndz, the oonly way tu reprezent them, whair thay ar not determind by pozishon at the end ov an oopen slabl, iz (az allreddy illustrated) by combining the letrz with different letrz, az we combiin in gain, real, mine, soar, rule; evidently gan, rel, min, sor, rul, woud not answer the purpus." 
No doubt orthographic reform in the way of elimination of useless letters is the shortest cut toward greater accuracy. But complete simplification to a pure phonetic basis is doubtful economy. Confusion and inconsistency are not eliminated by drastic phonetic reformation. The direction and extent of the reformation is evidently the task of the philologist; improvement in pedagogical technique would seem to be the domain of the educator. That the task of verbal simplification will be left to the philological expert and that the educator will confine his activity to the development of principles underlying the technique of spelling is asking too much of an age yet two-thirds scornful of expert guidance.

\section{Perpose}

The following observations of a six and one-half year old boy is an attrmpted analysis of certain factors in orthographic technique present in a child's initial spelling work. It should be said that the boy tested out seven and one-half years, according to the Binet-Simon test, and that he is now spelling with reasonable ease the ordinary list of words found in Jones's Third Reader. It should be added that less time was devoted per day than is usually given to exercises in spelling in the primary grades of the public schools.

The purpose of the experiment is to determine: (a) whether pupils in their initial spelling work should be permitted to form a general attitude toward a group of assigred words, or, (b) whether an independent specific attitude toward each word of a group should be developed. The characteristic feature of " $a$ " consists in a definite spacial and temporal relation of the words of an assigned lesson. What is the recall value of such a procedure as compared with a procedure in which each member of a group of assigned words is relatively independent of any such spacial and temporal orders?

Points " $a$ " and " $b$ " above may be illustrated by the following list of words:

1. missed

3. jackstraws

2. smell

4. evening

5. kennel

6. dominos

7. photographs

8. kingdom

9. march

10. games

It is obvious in the above list of words, as in any ordinary formal group of words found in our common school readers, 
that the group associates and the spacial order of the words are entirely accidental. There is no reason why any other order or any other words of equal difficulty might not with equal propriety and educational value be chosen. Of what advantage or disadvantage are the accidental features of a given list of words in recall-immediate, temporary, or peimanent? It is probable that each grouping in a given list of words has the same recall value as any other possible grouping of this list. It is probable, too, that any grouping whatsoever has only a temporary recall value. The fact that "missed" has the top space relation to "smell" has little, if any, permanent recall value, for the use of either word in meeting future situations may never involve the other in just this relationship. But experiment shows that this relationship has a temporary functional value in recall. What is true of the spacial order holds equally for the temporal order-both orders constituting accidental features in memorial imprinting and subsequent reproduction.

\section{Experimental Data}

The groups of words employed in this experiment are found in Jones's Second Reader. Not more than one group was assigned for any one lesson whether the group contained many or few words. In the first lesson the order given in the reader was followed in the assignment, in the study period, and in recall. On page 10, for example, the following group of words is found:
1. bumbleber
$3 \mathrm{~d} \ln$
5. purple
2 boom
4. need
6 rover

According to the first procedure the words are assigned, studied, and recalled in the order indicated by the prefixed numbers. In the seco'd lesson the words were considered during the assignment and study period in promiscuous order and recalled in chance order. The third lesson proceeded as in the first, the fourth as in the second, and so on through the reader. Close supervision during the study period insured the maintenance of these conditions. In the first case the procedure may be termed orderly assignment, orderly study, and orderly recall; in the second case the procedure is random assignment, random study, 
and random recall. The latter procedure more nearly parallels conditions of recall operative under actual situations of life. Obviously orthographic recall in actual situations has neither spacial nor temporal references such as are found in the former procedure.

One group of words was taken per day and at approximately the same hour. Upon completion of the reader the words were again recalled under similar conditions, but this time without previous study. Each group of words was twice recalled: first, immediately upon completion of the study period; second, subsequent to the completion of the text. Before taking up a new group of words the learner was required to reproduce correctly all of the words of a given group. Consideration of an assignment was complete upon the first correct reproduction of the entire list of words.

With words of the chance order grouping, attention was occasionally centered in a conversational way upon the importance of learning the words for "all time." Even at this early age some degree of attention to permanent retention appeared awakened in the mind of the learner, and it is not improbable that the effect of this attitude, however indefinite, manifested itself in greater efficiency in the reproductive process.

\section{Results and Discussions}

A total number of one hundred four groups of words were studied (Table I), fifty-four according to orderly procedure and an equal number according to random procedure. The following statements briefly summarize the results:

(a) In Immediate Recall

1. Total number of errors for all groups of words

. Number of errors when the procedure is orderly

. Number of errors when the procedure is orderly . . . . . 33

3. Number of errors when the procedure is random . . . . . 40

4. Excess of errors of " 3 " over " 2 ". . . . . . . . 7

5. Percentage advantage of " 2 " over " 3 "... . . . $\quad \ldots \ldots . .94$

6. Average words wrong $0.1 ;$ P. E. .07.

\section{(b) In Delayed Recall}

1. Total number of errors for all groups of words . $\quad . . .249$

2. Number of errors when the procedure 1s orderly.. . . . . . . . 145

3 . Number of errors when the procedure is random. .5104

4. Excess of errors of " 2 " over " 3 ". . . . . . . . . . . . . . .41

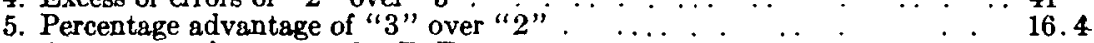

6. Average words wrong $031 ;$ P. E. .11 
(c) Comparison of (a) and (b).

1. Total number of words constituting the experiment. . . . . . . . . . 808

2. Total number of groups of words (separate lessons) $\ldots \ldots \ldots \ldots, \ldots \ldots 104$

3. Errors in delayed recall times greater than in immediate recall (orderly pro-

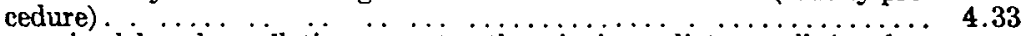

4. Errors in delayed recall times greater than in immediate recall (raudom

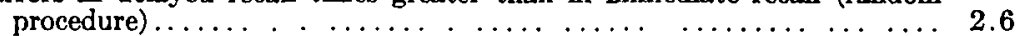

5. Relative advantage of the randorn method times that of the orderly method 1.73

In the case of immediate reproduction, the orderly procedure is more efficient by $9.4 \%$ than the random procedure; in the case of delayed recall the efficiencies of the two methods are reversed - the random exceeding that of the orderly procedure by $16.4 \%$. The advantage of the random method over that of the orderly in delayed recall as compared with the advantage of the orderly method over that of the random method in immediate recall is not adequately represented by the absolute values standing for the respective advantages of the two kinds of recall. Relatively, $1 \%$ advantage of the $16.4 \%$ has a higher practical significance than $1 \%$ of the $9.4 \%$ in so far as the former represents fairly permanent mental acquisition. The superiority of the orderly method in immediate recall is in large part due to the functional participation of accidental factors in perception. Chief among such factors are the spacial and temporal arrangements, which happen to prevail, in a given group of words. The superiority of the random method in delayed recall is in large part due to the fading away of the accidental factors which accompany the original learning according to the orderly method. These factors apparently serve an immediate need, then fade rapidly and almost wholly fail to function in delayed recall. According to the random method no such artificial crutch attends the original learning and therefore reproduction remains unaffected by its absence in delayed recall.

\section{Observations and Conclusions}

From the foregoing the assignment of a spelling lesson and the study period gain enormously in importance. The results of the experiment show that a part of the time of an assignment should be devoted to the prevention of the formation of fixed spacial and temporal arrangements of the words of a lesson. Such arrangement can serve no useful purpose in future recall. When, for example, an assignment is made in general terms 
TABLE I.

No. of mis- Per cent. of er- No. of mis-

\begin{tabular}{|c|c|c|c|c|c|}
\hline $\begin{array}{l}\text { No. of } \\
\text { Group }\end{array}$ & $\begin{array}{l}\text { No. of } \\
\text { words in } \\
\text { group }\end{array}$ & $\begin{array}{l}\text { spelled words } \\
\text { in group-1st } \\
\text { attempt, Im- } \\
\text { mediate res- }\end{array}$ & $\begin{array}{l}\text { rors in group- } \\
\text { immediate res- } \\
\text { toration }\end{array}$ & $\begin{array}{l}\text { spelled words } \\
\text { in group-de- } \\
\text { layed recall }\end{array}$ & $\begin{array}{l}\text { Per cent. of er- } \\
\text { rors in group- } \\
\text { delayed recall }\end{array}$ \\
\hline
\end{tabular}

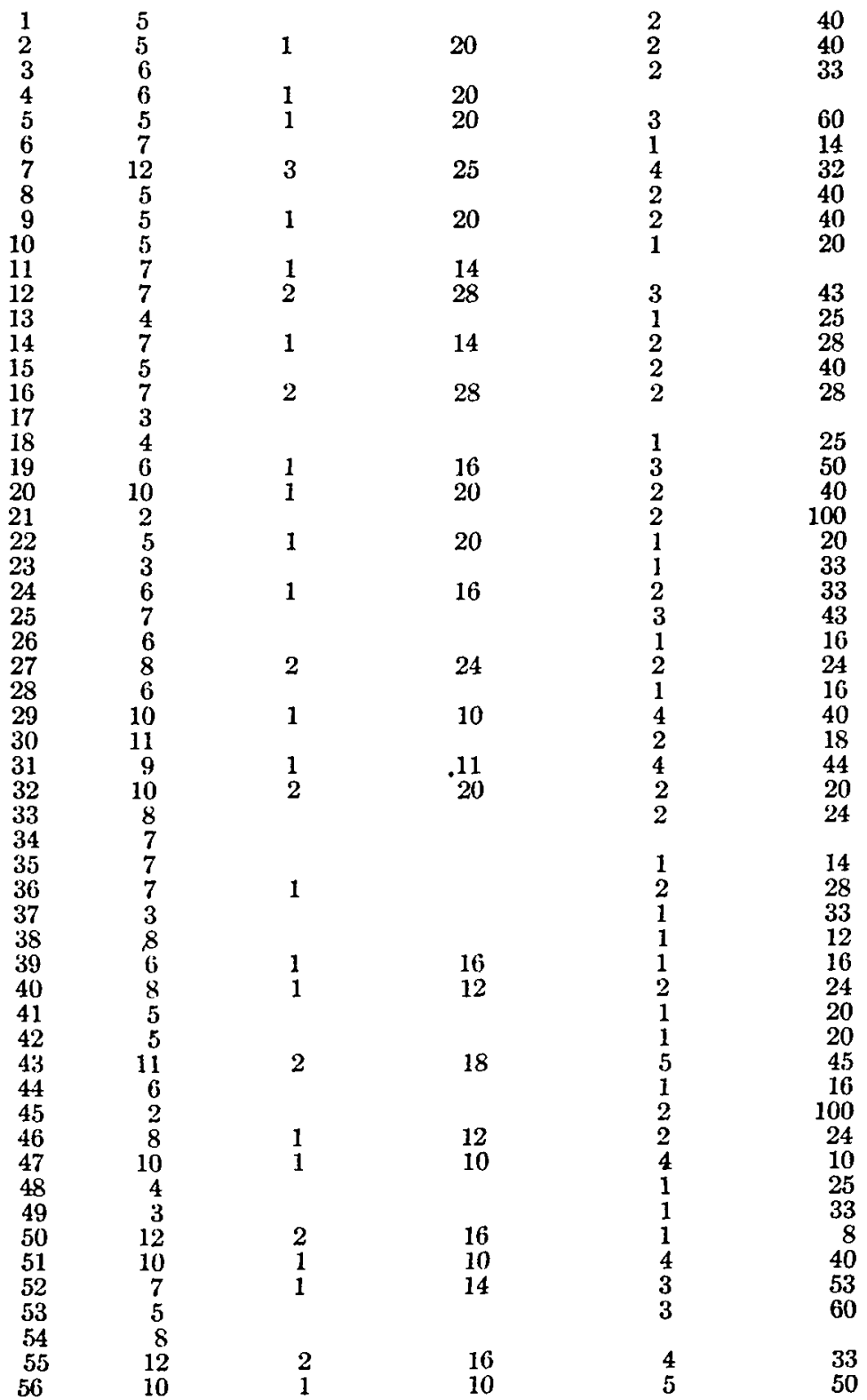




\section{(TABLE I-Continued.)}

No of No. of Group words in group spelled words in group-1st mediate restoration

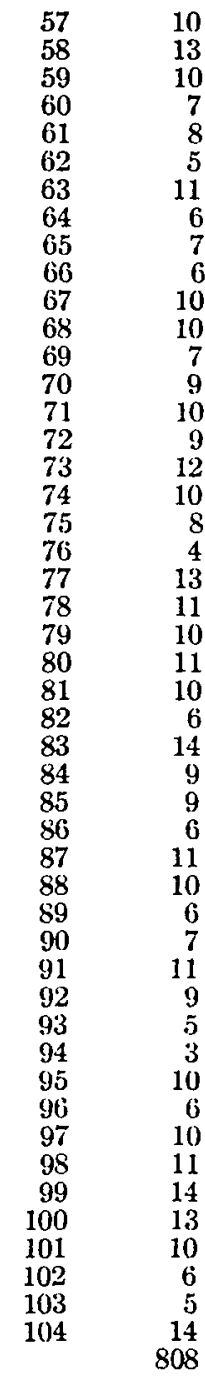

$13-4$

4

1

1

1

1

2

1

2

2
2
1

1

3

1

2

1

2
73
Per cent. of er- No. of misrors in group- spelled words mediate res-
toration
layed recall

$\begin{array}{ll}1 & 10 \\ 1 & 16\end{array}$

218

$\begin{array}{rr}1 & 7 \\ 2 & 15\end{array}$
14

10

22

8

31

14

20

15

18

10

21

9

10

14
440

22

43

25

20

18

48

28

30

20

28

33

30

11

1 (83)

33

20

37

25

46

54

40

18

30

16

28

22

44

32

36

20

50

28

18

44

60

66

30

50

40

27

43

31

50

50

28

Number of words spelled acrording to orderly procedure $=410$.

Number of words spelled according to random procedure $=398$.

Fractions neglected.

Odd numbered groups indicate a general, orderly attitude on the part of the learner. Even numbered groups indicate an individual, random attitude on the part of the learner toward the separate words of a group. 
such as "take the group of words at the top of the next lesson" to a class of primary pupils, a group attitude is established in which each of the words stands in a fixed space and time relation. Observation shows that this attitude is, within certain limits, maintained throughout the study period and caried over to the reproduction period. It is believed that the group attitude interferes with the pupil's independent analysis of each word during the study period and with recall during the recitation period. Accurate observational noting under the direction of the teacher is the first effective imprint received by the child. The effectiveness of subsequent impressions during the study period when the direction of the teacher is withdrawn will depend much upon the first impression. The assignment should be made in such a way as to insure specific adjustment to, and accurate noting of, each individual word of the group, dropping away, as it were, from the other words of the group. This may well be done by focalizing the pupil's attention on each separate word but in no particular space order. Moreover, the teacher should insist that no particular order be followed in learning during the study period.

Children, if left to their own devices, learn a series of words according to the order laid down in the text. If recall follows the order of learning, the efficiency for a given recall period is usually high; if the order of recall is varied, or there is no definite order, confusion is introduced and efficiency disturbed. The definite space order scheme has a relatively temporary learning value as is evidenced by the general inefficiency in subsequent reproduction in revifws.

The above list of words was learned in the order indicated by the numerals. When "March" in the reproductive order followed "missed" the pupil was at sea, confused, as is indicated by the statement, "I was thinking of "smell." Obviously we find here the order of learning interfering with the independent consideration of the word "March." This case is typical of a large number of similar observations. It appears that words should be learned at random, that is, independent of all associates other than the phonetic associates, unless such other associates form permanent and meaningful connections. It is clear that "missed" and "smell" form a unique, temporary, and accidental contiguity which can by no means function as an 
agent of recall in future situations. Such arbitrary contiguities function positively for a given spelling assignment, but the total final effect is negative in that they interfere with the establishment of clear and definite phonetic connections of the literal elements of a word. In fact, reliance on contiguity acts as a distraction to clear phonetic apprehension.

Observation shows that economy in learning to spell demands that each word be hoisted out of its group setting for the reason already given and for the equally or more important reason that by so doing the literal elements of a word are brought out into clearer consciousness and their phonetic connections established. The importance of raising the sounds and their connections into clearer consciousness by means of the assignment is obvious from the repeated confusion of the letters " $m$ " and " $n$," " $j$ " and "g," "in" and "m." The word "missed" was studied and reproduced as "nissed"; "jackstraw" as "gackstraw"; "games" as "gains." These cases clearly indicate the necessity of attentive focalization on the structural elements of each word prior to the study period if progress in spelling is to be economic, rapid, and permanent. In this connection it should be remembered that a single focalization by no means establishes the phonetic associates of a given word. Repetitive focalization is best secured by having several pupils successively pronounce and phonetically spell in irregular order the various words of a given group. The profit of the study period is proportional to the eare with which this part of the assignment is carried out. It is perhaps safe to say that one-half of the time devoted to second grade spelling should be devoted to the assignment.

\section{Summary.}

1. Within the limits of this study a group attitude toward a given list of words is more efficient in immediate and less efficient in delayed recall.

2. An individual, particular attitude toward each member of a group independent of spacial and temporal relations is more efficient in delayed recall and less efficient in immediate reproduction.

3. Whether the orderly or random method is preferable depends upon the end or purpose of the learning. If the end is 
a perfect recitation without regard to lasting effect, then the orderly procedure saves time and energy and should be followed; if, however, the end is permanent retention and accuracy in reproduction, then the random procedure should be followed. Here as elsewhere in educational technique the purpose in learning determines the method. A given method of learning may be economical when one effect is desired and uneconomical when another effect is sought. 